\title{
Migrações culturais e leituras comparatistas
}

\author{
SALETE CARA \\ Universidade de São Paulo
}

\begin{abstract}
RESUMO: A COMPARAÇÃO ENTRE O PROJETO COMPARATISTA DE JOÃO RIBEIRO E A LEITURA DE SERGIO BUARQUE DE HOLANDA EM RELAÇÃO À PRODUÇÃO DO ARCADISMO BRASILEIRO LEVA A PENSAR NAS DIFERENÇAS ENTRE O NACIONALISMO EMBUTIDO NA VISÃO CULTURALISTA DO PRIMEIRO E O MÉTODO HISTÓRICO-ESTÉTICO PRESSUPOSTO PELO SEGUNDO.
\end{abstract}

RESUMEN: EL COTEJO ENTRE EL PROYECTO COMPARATISTA DE JOÃO RIBEIRO Y LA LECTURA DE SERGIO BUARQUE DE HOLANDA EN RELACIÓN A LA PRODUCCIÓN DEL ARCADISMO BRASILERO HACE PENSAR EN LAS DIFERENCIAS ENTRE EL NACIONALISMO QUE SE OCULTA EN LA VISIÓN CULTURALISTA DEL PRIMERO Y EL MÉTODO HISTÓRICO-ESTÉTICO PRESUPUESTO POR EL SEGUNDO.

PALAVRAS-CHAVE: COMPARATISMO, CULTURA, NACIONALISMO, MÉTODOS CRÍTICOS, HISTÓRIA.

PALABRAS-CLAVE: COMPARATISMO, CULTURA, NACIONALISMO, MÉTODOS CRÍTICOS, HISTORIA. 
m pequenos textos de 1905 e 1910, publicados em Páginas de estética e em $O$ Fabordão (crônica de vário assunto), João Ribeiro esboçou o que pode ser considerado o primeiro projeto comparatista da Literatura Brasileira. Os textos são curtos e enfrentam um assunto vastíssimo com impressionante à vontade, revelando uma ousadia que dá dimensão do vigor e também dos limites do imaginário crítico da época. O crítico que tinha chegado no Rio de Janeiro em 1880, vindo de Sergipe, encontrou alguma resistência entre seus companheiros letrados: José Veríssimo e Araripe Júnior, por exemplo, comentaram as manias classicizantes e o germanismo de João Ribeiro, mas com todo o respeito pelos seus vôos eruditos. De fato, ele parecia antiquado para aqueles que, desde a geração de 1870, estavam sempre procurando atualizar os rumos das suas reflexões sobre a nação.

No texto "Literatura comparada", publicado em 1905, João Ribeiro funda seu comparatismo no pressuposto de uma literatura comum ocidental, nascida da "montanha do inconsciente", e ratifica o papel da tradição popular do medievo, tal como o tinha feito a cultura burguesa européia, a partir do século XVIII, ao buscar o local originário de sua identidade. Conceitos românticos como "alma popular" ou "imaginação coletiva" encontram correlato em "alma nacional", mas ao mesmo tempo, passando ao largo da história e de qualquer viés historicista, o comparatismo do crítico ia na contramão da preocupação romântica com o "fator nacional" e com a questão da originalidade.

A transposição extemporânea de conceitos românticos escancara seu caráter abstrato. É verdadeiramente curioso que, para livrar-se do rótulo "literatura nacional" ele escreva, em 1910, que "uma literatura nacional é quase antinomia paradoxa e absurda, porque não há patriotismo intelectual" , retomando idéias expostas em dois artigos que tinha enviado da Alemanha nos fins da década de 80: o "patriotismo é sentimento mortal na América...Ou a América será cosmopolita, ou não será". Anote-se que essa mesma matriz marca fundo, já na primeira década de 1900, o interesse de João Ribeiro pelas manifestações do folclore.

O crítico quer, antes, justificar a integração de "selvagens, bárbaros ou civilizados, homens enfim" numa mesma "alma popular", tal como anuncia-

\footnotetext{
${ }^{1}$ Cf. RIBEIRO, João. 'Literatura comparada”. Revista Brasileira. Rio: quarto ano, tomo décimo terceiro, 1898.
} 
ra no capítulo de 1905, quando tinha proposto a comparação entre uma "literatura orgânica, popular, espontânea" e "essa outra literatura nossa, erudita, refletida, artificial, tardiamente criada, sobreposta e dobrada sobre a grande arte popular", tomando como referência estudos de românticos alemães interessados nas "nascentes e caudais da poesia e da prosa popular" de origem medieval - "uma literatura inconsciente, não escrita, secular", ou ainda "uma literatura comum, como havia uma cristandade e um latim para todos". Para todos?

Cinco anos mais tarde escolhe os séculos XVII e XVIII para dali tirar exemplos de "paralelismos literários", defendendo um método de investigação capaz de fundir as especificidades do tempo e do espaço numa dimensão que os transcendesse. Um método que observaria a "expansão", sem limites, dos "períodos históricos das literaturas" e suas "interpenetrações mútuas": Gregório de Matos e Gôngora, Gonzaga e Anacreonte. A universalidade das convenções barroca e árcade sugeriu ao crítico a própria medida da universalidade da produção nacional, e lhe pareceu confirmar as condições de igualdade das produções culturais ocidentais. A convenção literária garantiria, ela mesma, a manutenção de um princípio artístico universal a despeito da diversidade de espaço e mesmo de tempo histórico.

O desejo de unidade e harmonia da ordem cultural global manifestado por João Ribeiro vinha, sem dúvida, a serviço da negação da precariedade da Civilização brasileira. Vê-se a urgência que tem em incluir, no filão ibérico e nobre de "Cultura", as produções literárias do país onde parecia tardar muito a chegada da "Civilização". Retomo os termos "Cultura" e "Civilização", pontual e propositalmente no seu sentido antagônico tradicional, tal como foram repostos em circulação por João Ribeiro a partir de suas leituras alemãs. Foi decisiva a primeira viagem que fez à Alemanha, em 1895, como representante do Congresso de Propriedade Literária em Dresde, quando morou no país por um ano. Ali João Ribeiro se entusiasmou, anacronicamente, pelo conceito de cultura que vinha de Herder, como contraponto do conceito de Civilização, que correspondia a progresso material e técnico.

Desse modo a precariedade nacional, tema e motivo recorrentes nas obras de seus pares, acabava diluída na idéia de uma origem comum e de uma consonância universal dos fatos de cultura: "ondeou o mesmo pensamento artístico, 
lá alteroso, aqui simples ou rude". Nessa pequena afirmação, todavia, os critérios das qualificações que distinguem "lá" e "aqui" - a saber, "alteroso" (lá) e "simples ou rude" (aqui) - não são expostos pelo crítico. O que importa é a sugestão de que o "pensamento artístico" seja "o mesmo", lá e aqui. Para tanto, vale aquele conceito de matriz popular como substrato cultural único e amplo, orgânico e inconsciente, atemporal e transnacional, que funde convenientemente o "alteroso" e o "simples e rude", seja lá o que possam significar esses termos.

Coerentemente no âmbito desse esquema, para João Ribeiro "os mesmos materiais" viajam, sempre iguais, pelo tempo e pelo espaço. Cabe acentuar que, para tanto, é fundamental que os "materiais" sejam "idéias", e que essas "idéias" por sua vez sejam concebidas acima do bem e do mal, já que são elas que "fertilizam" o tempo (a história) e o espaço (as regiões). Ainda segundo o crítico, examinando as "interpenetrações mútuas" dos "períodos históricos", poderíamos ver que "cada idéia nos grandes povos tem sempre um centro de irradiação que expira muito além das fronteiras". Nesse passo João Ribeiro se desfaz do conceito de originalidade, rebaixando a importância do "meio" tão cara a Taine e àquela geração crítica.

Ao exemplificar seu projeto comparatista com dois breves textos (Gôngora e Gregório de Matos; Gonzaga e Anacreonte), ele desqualifica, ao mesmo tempo, originalidade e meio. A primeira existiria "apenas na cor local: a diferença de meio é, sem dúvida, a única excentricidade humana”. Originalidade, tempo e espaço resumem-se a "apenas". Vou tomar como exemplo o tratamento que confere ao século XVIII, já que ali o crítico é desafiado a lidar com a inserção inevitável, no largo e milenar fluxo da criação cultural do Ocidente, das literaturas dos países coloniais ainda em processo de formação. Como o faz?

No texto sobre Gonzaga, publicado em O Fabordão, o poeta aparecerá como o melhor tradutor/imitador de um Anacreonte disseminado em inúmeras redes de leituras no período da decadência grega e, depois, em traduções modernas, desde a descoberta dos manuscritos apócrifos das odes por Henri Estienne no século XVI. Em nenhuma das imitações, traduções, versões e paráfrases de uma pequena ode de três versos João Ribeiro encontra intérprete-parafraseador à altura de Gonzaga! $\mathrm{O}$ argumento é sempre o de uma cultura comum: "As literaturas são menos nacionais do que levianamente se presumem: tem um fundo comum que é a unidade psicológica da civi- 
lização. (...) É o próprio interesse humano que dilui as fisionomias na alma sempre igual da cultura". ${ }^{2}$

Cabe perguntar: não seria essa rota apenas uma alternativa para a mesma preocupação nacionalista tão própria dos homens empenhados do tempo, e tida por progressista no âmbito literário? A hipótese não é desprezível. O esboço de projeto comparatista de João Ribeiro parece ser mais um esforço para driblar (e não necessariamente negar) a "questão nacional" na qual estava mergulhada toda a sua geração. Questão varrida para debaixo do tapete e posta de quarentena, até segundo aviso. ${ }^{3}$

Afinal, em 1906, Sílvio Romero teve o próprio João Ribeiro como co-autor de um livro com finalidades didáticas, o Compêndio de História da Literatura Brasileira, que escancarava toda a força e vigência do modelo historiográfico nacionalista, naturalista e evolucionista da História da Literatura Brasileira (1888) de Sílvio Romero. Nelson Romero afirma ter sido de João Ribeiro a autoria dos capítulos do Compêndio que tratam dos séculos XVI, XVII, XVIII e dos poetas da fase romântica. E assim como no $2^{\circ}$ volume da História da Literatura, Romero creditava o vigor nacional do lirismo árcade aos assuntos e à tradição popular nacional, mais do que à presença de uma matriz clássica, também no Compêndio é "um sentimento [nacionalista] subjetivo, forte e incoercível" que marca a "escola mineira”! Nas duas páginas sobre Tomás Antonio Gonzaga são retomados dois parágrafos inteiros da História da Literatura. Um deles: "o defeito capital do lirismo mineiro do século XVIII é certa falta de variedade, e esta mácula nota-se também em Gonzaga. Seus versos são queixas à sua Marília derramadas por um volume inteiro". ${ }^{4}$

\footnotetext{
${ }^{2}$ Cf. RIBEIRO, João. "Gregório de Matos e Luis de Gôngora”, O Fabordão (crônica de vário assunto). 2.ed., Rio: Livraria São José, 1964. p.307., Cf. Revista Brasileira. Rio de Janeiro: quarto ano, tomo décimo terceiro, 1898, p. 98.

${ }^{3}$ E voltará de fato, mas de outro modo, quando em 1928 escreve sobre Oswald de Andrade: "É certo que houve algum contrabando europeu, mais ou menos disfarçado, mas deu aos poetas novos a esperança de viverem sobre si, à custa do trópico, sem adaptações escandalosas. Eis o serviço que ele prestou, sorrindo, e que provavelmente não sabia tê-lo prestado. Atirou no que viu e matou o que não viu. Assim Oswald de Andrade despertou um eco quase patriótico. Fez, sem querer, uma revolução." Cf. Crítica (Os Modernos), LEÃO, Múcio (Org.). Rio de Janeiro: Academia Brasileira de Letras, 1963, p. 91.

${ }^{4}$ Cf. ROMERO, Silvio.; RIBEIRO, João. Compêndio de Historia da Literatura Brasileira. Rio: Livraria Francisco Alves, 1906. p. 79 e p. 82 e ROMERO, Silvio. História da Literatura Brasileira,. 7. ed., Rio: José Olympio, 1980, p.453 e p. 458, vol. 2.
} 
Quarenta anos mais tarde, Sergio Buarque de Holanda iria debruçar-se também sobre o Arcadismo. Os ensaios escritos entre os anos 40-50 ficaram inéditos até 1991, quando foram publicados em volume organizado e prefaciado por Antonio Candido, para quem o Arcadismo brasileiro foi "uma espécie de identificação com o mundo europeu através do seu homem rústico idealizado na tradição clássica", como afirmou numa entrevista a Beatriz Sarlo em 1980. O caráter paradoxal da literatura neoclássica entre nós consistiu no fato de que, ao "juntar a tradição européia com o país em formação", acabou transformando-se em "fator nacional". 5

Para Sergio Buarque é justamente essa a tensão que o crítico deve enfrentar ao ler os árcades brasileiros: "a amargura contra a condição de peregrino na própria terra responde a uma simples convenção literária”. A consideração dessa tensão era exigida pela própria poesia do século XVIII, de modo que o crítico não procura um universalismo sem diferenças, nem transforma o "fator nacional" numa busca de essencialidades, o que levaria a privilegiar o Romantismo em detrimento do Arcadismo. Segundo Antonio Candido, não teria sentido opor de modo purista, a um Romantismo nacionalista, um Arcadismo alienador e artificial como mera expressão de subserviência e colonialismo:

A afirmação costumeira que este ou aquele "momento" possui maior ou menor autenticidade nacional pode trazer no subsolo o pressuposto (super-idealista) de uma espécie de "alma nacional", mais patente em dado momento literário (o latino-americano sendo "barroco", ou "lírico", ou "melancólico" ou "primitivo"). E acaba-se numa busca de essências. ${ }^{6}$

Contra tais essencialidades, e reconhecendo o papel da convenção árcade na tradição culta ocidental, o caráter hegemônico do projeto neoclássico,

\footnotetext{
${ }^{5}$ Cf. CANDIDO, Antonio. "A literatura e a formação do homem". Textos de intervenção. São Paulo: Duas Cidades/ Editora 34, 2002, p. 84. Cf. no mesmo volume "Variações sobre temas da Formação", p. 9495 (seleção, apresentação e notas de Vinicius Dantas).

${ }^{6}$ CANDIDO, Antonio. "Historia de la literatura latinoamericana". PIZARRO, Ana. Hacia una historia de la literatura latinoamericana. Cidade do México: El Colégio de Mexico/Caracas, Universidad Simon Bolívar, 1987. A referência é parte de uma fala proferida numa reunião em Caracas. Cf. Textos de intervenção, op. cit., p. 98
} 
racional e moderno no século XVIII, e o processo de fixação literária dos "arquétipos da imaginação", Sergio Buarque de Holanda faz a exigência de um método crítico estético-histórico. Vejamos: mergulha a produção árcade no caudal literário europeu ocidental, incluída aí a Itália como berço, vê o Classicismo francês, de herança cartesiana, reelaborado e também rechaçado por italianos e espanhóis. Nesse passo, acentua a relação entre tradição lusitana e brasileira, sem deixar de apontar que a noção de "bom gosto" dos árcades tinha sido proposta pelo espanhol Baltasar Gracián, codificador cultista. Ao mesmo tempo, insiste para que fiquem visíveis "as características próprias das diferentes épocas", e que não se dissipem "contrastes que se escondem sob afinidades aparentes e tantas vezes ilusórias".

As convenções literárias, fosse nos países de onde se originaram, fosse naqueles por onde passaram com mais força, não deixam de ser...convenções! "A poesia bucólica é tão artificial na América quanto na França ou na Espanha". Ainda assim, uma convenção ou um conceito, ainda que parecesse ser o mesmo, corresponderia a coisas diferentes em experiência diversas. O que leva Antonio Candido a comentar que Sergio Buarque estaria desencorajando "os caçadores de prés e pós no estudo das fases literárias". No trabalho de Sergio Buarque fica implícito que as relações entre local e universal são mediadas, e não diretas, e que os próprios instrumentos literários convencionais estão carregados de sentidos histórico-estéticos dos tempos e lugares por onde passam. ${ }^{8}$

Nesse mesmo espírito pergunta por que, afinal, a convenção arcádica teria se aclimatado tão bem num país colonial, "onde a natureza primitiva ou mal domada era uma realidade onipresente e bastante crua para tolerar daqueles louvores, próprios de cortesãos"? Por que a idealização do mundo rústico causou um "efeito estimulante" na "inculta América" ? A resposta do crítico, anote-se, pressupõe olhar a entronização do imaginário árcade tanto em terras européias quanto brasileiras, pois "a rusticidade galante e polida que o

\footnotetext{
${ }^{7}$ Cf. HOLANDA, Sergio Buarque de. Capitulos de Literatura Colonial. São Paulo: Brasiliense, 1991, p. 223. Organização e introdução de Antonio Candido.

${ }^{8}$ Id. Ibid.
} 
Arcadismo cultivou parecia tão longe da nossa rusticidade real quanto o era das sociedades mais cultas".?

O que se modifica portanto de um lugar a outro, de um tempo a outro, são as condições de acomodação de uma convenção. No caso da poesia setecentista, ela acabou sendo, entre nós, categoria mediadora da própria experiência particular dos nossos homens cultos, letrados exilados na sua própria terra. Relação complexa que dá lugar a um sentimento que, pela primeira vez na literatura brasileira, sustenta obras que não são "meros pastiches":

É provável que o simples fato de engrandecer, idealizando-o embora, um mundo rústico e de opô-lo aos requintes da corte e das cidades, tenha tido sobre alguns homens da "inculta América" efeito estimulante, livrando-os dos sentimentos de insegurança e inferioridade, que os faziam sentir-se desterrados na sua terra". ${ }^{10}$

O problema proposto por Sergio Buarque é de grande alcance: o sentimento de exílio no próprio país começava a ser penosamente elaborado através de convenções de tamanha artificialidade que, através delas, aqueles homens cultos puderam imaginar "a consciência nova de suas possibilidades e dos seus direitos"! Uma originalidade que escapa ao olhar mais superficial. Entre a tradição ocidental posta em circuito - com intrincados caminhos de ecos milenares que chegam à Península Ibérica cruzando, muitas vezes, as criações populares - e a experiência posta em poesia pelo poeta desterrado na sua própria terra, Sergio Buarque constata mais do que mera repetição de tópicos clássicos.

Citando a edição da obra de Cláudio Manuel da Costa, de 1903, feita por João Ribeiro para a Academia Brasileira, ele ratifica a afirmação do crítico sergipano, segundo a qual a paisagem brasileira "não cabe em sua estética", e sem negar o "enamoramento" de Gonzaga pelos princípios arcádicos, mos-

\footnotetext{
${ }^{9}$ Cf. HOLANDA, Sergio Buarque de. Capitulos de Literatura Colonial. São Paulo: Brasiliense, 1991, p. 225. organização e introdução de Antonio Candido.

${ }^{10}$ Id. Ibid.
} 
tra que sua poesia amadurece justamente quando o poeta chega como ouvidor em Vila Rica, em 1782. Interessado em perceber o modo como se dava a configuração das particularidades da colônia, na medida mesma da sua integração à convenção literária do tempo, mostra como $A$ Fábula do Ribeirão do Carmo acomoda as leis da convenção arcádica às exigências ao sentimento íntimo, à "amargura contra a condição de peregrino na própria terra". ${ }^{11}$

Ao ler a poesia de Cláudio Manuel da Costa mostra que ela é atravessada por cadências, qualificativos, esquemas de rima e retomadas de temas que, no entanto, tinham passado também pelos seiscentistas, alertando porém:

O recurso à convenção não explica suficientemente, porém, o caráter verdadeiramente obsessivo que assume em sua obra, mesmo comparada à dos quinhentistas e à dos clássicos latinos e gregos, aquele tema do desengano e o do desespero sem remédio. ${ }^{12}$

Num âmbito mais geral, Sergio Buarque de Holanda pôde ver a "atmosfera de todo o século XVIII" em "manifestações mais diversas e mesmo antitéticas" do tempo, quais sejam a Arcádia, a Declaração dos Direitos do Homem (realçando a conotação política aos "direitos naturais e imprescindíveis") e a Independência dos Estados Unidos com suas "leis da Natureza e do Deus da Natureza". Afunilando em termos literários, a reflexão crítica exposta em "O ideal arcádico" ilumina seu próprio procedimento crítico. Diz ele que, se o crítico recorta um período histórico-artístico em função de uma unidade que queira estabelecer entre alguns de seus elementos formadores, deve dar por sabido que esses são formas em tensão: formas da organização social, valores, convenções e materiais de trabalho disponíveis para o artista naquele momento ("a seda, o vidro, a porcelana, a madrepérola, a madeira substituindo em grande parte a pedra").

Uma perspectiva crítica unificadora poderia apaziguar as próprias "formas discordantes, conquanto que, logo em seguida, possam recuperar sua indepen-

${ }^{11}$ Cf. HOLANDA, Sergio Buarque de. Capitulos de Literatura Colonial. São Paulo: Brasiliense, 1991, p. 234. Organização e introdução de Antonio Candido.

${ }^{12}$ Id. Ibid. 
dência e que o artifício provisório não se converta em fatal armadilha para quem dele se serviu". Por isso Sergio Buarque critica a leitura feita por Teófilo Braga da obra teatral de Antonio José, o Judeu, onde o crítico português destaca a importância da modinha escutada pelo escritor na infância brasileira. A modinha, "fruto do gênio português" segundo Braga, teria sido preservada no Brasil como costume popular. Sergio Buarque então observa:

As expressões poéticas desse misterioso "gênio" são idealmente imóveis e, salvo em condições privilegiadas de segregação, como as que se teriam verificado, de algum modo, no Brasil ou nos Açores, não podem transformar-se, embora sujeitas a corromper-se ao contato com as formas eruditas, cortesãs e cosmopolitas. E, assim, somos reconduzidos, de qualquer modo, à velha posição romântica e herderiana que se supunha superada. ${ }^{13}$

A leitura de Sérgio Buarque sobre o Arcadismo, não prescinde da história: são primorosos os parágrafos onde, com humor calculado, ele retoma as descrições florais do bosque Parrásio tal como o encontrou Vernon Lee quando, por volta de 1880, pesquisou o Setecentismo na Itália, narrando suas próprias aventuras como pesquisador brasileiro, e registrando o sumiço do retrato do benfeitor D. João V, que tanto auxiliara a Arcádia Romana... com as riquezas tomadas do Brasil.

Ao lembrar-se com admiração e respeito de João Ribeiro como o senhor com quem conversava na redação do Jornal do Brasil, aconselhando-o a guiar-se pela eufonia no caso de dúvida sobre ser ou não correta uma forma lingüística, Sergio Buarque de Holanda acentua as diferenças entre sua própria formação e a do velho crítico, jornalista, gramático e historiador que morreu nos anos 30. Para tanto leva em conta sobretudo a situação geracional de um e de outro:

Meus pontos de vista e meus critérios de julgamento destoavam bastante dos seus e, em geral, dos homens de sua geração, uma geração cujos mais ilustres

${ }^{13}$ Cf. HOLANDA, Sergio Buarque de. Capitulos de Literatura Colonial. São Paulo: Brasiliense, 1991, p. 193. Organização e introdução de Antonio Candido. 
representantes se tinham formado, intelectualmente, na leitura de Spencer, Taine, Renan, às vezes Buckle, entre outros, estranhos ao círculo de minhas preocupações. Só na idade madura, se não já na velhice - que freqüentemente serve de resguardo contra a injúria dos tempos -, se viu ela surpreendida pelo furacão da Primeira Guerra Mundial, que desmascarou as ilusões do progresso, abalou o sentimento de segurança e fez com que se desvanecesse toda esperança em dias melhores. Preso, embora, às imagens de um passado próximo, nas aparências, mas para os moços já bem remoto, João Ribeiro não deixava de vislumbrar a facticidade da condição gerada por essa herança. ${ }^{14}$

Digamos que o comentário do crítico antecipa a falência das nossas "ilusões do progresso", que se configurou bem mais tarde (e para quem foi capaz de ver). Essas ilusões é que deixavam muito visível o caráter anacrônico e regressivo do viés comparatista esboçado em 1905 e 1910 por João Ribeiro. A marcha dos tempos levou o crítico sergipano a abdicar definitivamente desse projeto enquanto, como crítico, continuou testemunhando às vezes com ceticismo, os impasses mal resolvidos do país. Nesse sentido seria curioso observar o modo como foi capaz de receber os escritores dos anos 20 e dos anos 30.

O que espanta no entanto é que, em alguns pontos, aquele projeto comparatista de João Ribeiro parece ser nosso contemporâneo, isto é, parece fazer parte do tempo presente dado a pós- modernidades, no seu esforço por salvaguardar uma pretensa dimensão autônoma da cultura e ignorar as peculiaridades efetivas da nossa inclusão rebaixada no circuito da modernidade. Deslocando a ênfase nacionalista para uma ênfase internacionalista, ou vice-versa, a insistência comum é ver, na produção cultural, uma tábua de salvação.

${ }^{14}$ Cf. HOLANDA, Sergio Buarque de. Tentativas de mitologia. São Paulo, Editora Perspectiva, 1979, p. 21-22. 